REVISTA DE DERECHO UNED, núm. 3, 2008

\title{
EL NUEVO RÉGIMEN DE DERECHOS Y LIBERTADES DE LOS INMIGRANTES
}

\author{
JuAn Miguel GoIg Martínez ${ }^{1}$
}

Resumen: El TC ha resuelto los recursos de inconstitucionalidad interpuestos contra la L.O. 4/2000 sobre Derechos y Libertades de los extranjeros en España y su integración social, en su versión dada por L.O. 8/2000. En sus resoluciones, el TC no sólo ha sentado un nuevo estatus en materia de derechos y libertades de los inmigrantes, sino que también ha modulado las potestades del legislador orgánico de los derechos.

Palabras clave: Palabras clave: Inconstitucionalidad, nulidad, inmigración, estatus constitucional, derechos y libertades, límites al legislador.

Abstract: The Spanish Constitutional Court has come to conclusions regarding the no constitutional appeal promoted against Organic Law 4/2000 related to Rights and Liberties for foreiners in Spain and their social integrationin its version given by Organic Law 8/2000. In their resolution, the Spanish Constitutional Court has not only fixed the bases of a new status in rights and liberties for foreiners but also has defined the faculties from Court and Law/Justice.

SUMARIO: I.- ANTECEDENTES; II.- LOS DERECHOS DE LOS INMIGRANTES EN LA LEGISLACIÓN ESPAÑOLA DE EXTRANJERÍA. 1.- La libertad y los límites del legislador en la jurisprudencia del Tribunal Constitucional; III.- EL NUEVO RÉGIMEN DE DERECHOS Y LIBERTADES DE LOS INMIGRANTES EN LA RECIENTE

1 Profesor Titular de Derecho Constitucional. Departamento de Derecho Político. Facultad de Derecho de la UNED. 
JURISPRUDENCIA DEL TRIBUNAL CONSTITUCIONAL. 1. Presupuesto impugnatorio. 2.- Contenido de las resoluciones. 3.- Efectos de las sentencias. Un nuevo régimen de derechos y libertades para los inmigrantes.

\section{ANTECEDENTES}

Como ha indicado el TC, el art. $13 \mathrm{CE}$, al establecer que "Los extranjeros gozarán en España de las libertades públicas que garantiza el presente título en los términos que establezcan los tratados y la ley», está consagrando un estatuto constitucional de los extranjeros en España.

En el Fundamento Jurídico 4 de la STC 107/1984, de 23 de noviembre, el TC establecía una clasificación de los derechos de los extranjeros, indicando que:

«Existen derechos que corresponden por igual a españoles y extranjeros y cuya regulación ha de ser igual para ambos; existen derechos que no pertenecen en modo alguno a los extranjeros( los reconocidos en el art. 23 de la Constitución, según dispone el artículo 13.2 y con la salvedad que contienen) existen otros que pertenecerán o no a los extranjeros según lo dispongan los tratados y las leyes, siendo entonces admisible la diferencia de trato con los españoles en cuanto a su ejercicio»

Nuestra jurisprudencia constitucional, ha reiterado que existen derechos del Título I que «corresponden a los extranjeros por propio mandato constitucional, y no resulta posible un tratamiento desigual respecto de los españoles" (STC 107/1984) puesto que gozan de ellos "en condiciones plenamente equiparables [a los españoles]» (STC 95/2000). Estos derechos son los que «pertenecen a la persona en cuanto tal y no como ciudadanos, o dicho de otro modo, se trata de derechos que son imprescindibles para la garantía de la dignidad humana que conforme al art. 10.1 de nuestra Constitución es el fundamento del orden político español» (SSTC 107/1984; 99/1985,; y 130/1995), o derechos «inherentes a la dignidad de la persona humana» (STC 91/2000). En esta situación se encontrarían el derecho a la vida, a la integridad física y moral, a la intimidad, la libertad ideológica (STC 107/1984), pero también el derecho a la tutela judicial efectiva (STC 99/1985) y el derecho instrumental a la asistencia jurídica gratuita (STC 95/2003), el derecho a la libertad y a la seguridad (STC 144/1990, de 26 de septiembre), y el derecho a no ser discrimi- 
nado por razón de nacimiento, raza, sexo, religión o cualquier otra condición o circunstancia personal o social (STC 137/200). Todos ellos han sido reconocidos expresamente por el TC como pertenecientes a las personas en cuanto tal, pero no constituyen una lista cerrada y exhaustiva.

El TC también ha establecido que, además de los derechos que no pertenecen en modo alguno a los extranjeros, existirá otros derechos y libertades, que pertenecerán, o no, a los extranjeros según lo dispongan los tratados y las leyes, por ser derechos de configuración legal. Este grupo de derechos y libertades, es el que mayor dificultades plantea, ya que al constituir todos ellos derechos de «configuración legal", el TC admite diferencia de trato, en cuanto a su ejercicio, por decisión libre y propia de la ley, y del Derecho convencional.

Sin embargo, también el TC ha admitido que nuestro ordenamiento no desconstitucionaliza el régimen jurídico de los extranjeros, el cual tiene su fuente primera en el conjunto del texto constitucional. En concreto, la titularidad y el ejercicio de los derechos fundamentales de los extranjeros en España deben deducirse de los preceptos que integran el Título I, interpretados sistemáticamente. Para su determinación debe acudirse en primer lugar a cada uno de los preceptos reconocedores de derechos que se incluyen en dicho Título, dado que el problema de su titularidad y ejercicio «depende del derecho afectado" (STC 107/1984).

Como ya en su momento expusimos ${ }^{1}$, los inmigrantes que se encuentran en territorio español disfrutan de los derechos y libertades que reconoce la Constitución en su Título I, puesto que es la Constitución el principal parámetro al que hay que acudir en la labor interpretativa del precepto. A pesar de la ambigüedad e indeterminación del texto constitucional, la remisión que el artículo 13.1 hace a la ley, no supone desconstitucionalizar la posición jurídica del inmigrante, de modo que los derechos y libertades de que son titulares serán aquellos que garantiza el Título I CE. El reconocimiento y disfrute de los derechos y libertades se debe hacer en los propios términos fijados por la Constitución, sin que la ley, en ningún momento, pueda restringir o configurar lo que la Constitución no restringe o configura, y así deberá ser entendido el alcance de los derechos y libertades de los inmigrantes.

1 Goig Martínez, J. M. Derechos y libertades de los inmigrantes en España. Una visión constitucional, jurisprudencial y legislativa, Universitas Internacional, Madrid, 2004, pág. 41. 
La Constitución constituye el parámetro para la fijación del estatus de los derechos y libertades del inmigrante. Y en cuanto parámetro primero y primario para la determinación de este estatus, el artículo $13 \mathrm{CE}$ no es el único precepto que determina de qué derechos y libertades son titulares los inmigrantes que se encuentran en territorio español, ni cómo podrán ser ejercidos. Por el contrario, una interpretación sistemática de la Norma Suprema implica que en la determinación de este estatus habrá que atenerse a la voluntad y el deseo de los constituyentes, expresado en el artículo 10.1 que convierte a la dignidad del hombre y los derechos que le son inherentes en fundamento del orden político y de la paz social, pero también, en el propio Preámbulo y en el artículo 1.1, tanto al definir el modelo de Estado, como al proclamar los valores superiores del ordenamiento jurídico -en especial la libertad y la igualdad-, así como en la sumisión y vinculación que para los poderes públicos suponen los derechos y libertades constitucionales, y los mandatos derivados de los artículos 9 y $53 \mathrm{CE}$, todo ello sin olvidar la posición que respecto a los derechos y libertades ocupan, como criterio interpretativo, los Tratados y Acuerdos Internacionales en materia de derechos, de los que España es parte, y que integran nuestro ordenamiento jurídico (art. $96 \mathrm{CE})^{2}$.

El alcance de los derechos de los inmigrantes, no puede ser configurado por los Instrumentos Internacionales sobre la materia o por la ley, puesto que son derechos constitucionales, por ello, la remisión realizada por el art. 13.1 CE a los Tratados y a la ley, no puede ser aplicada con esta generalidad que parece derivarse del precepto constitucional, y ello obedece a varias razones.

Los inmigrantes que se hallen en territorio español, por encontrarse bajo la jurisdicción del Estado español, son titulares de derechos fundamentales y de libertades públicas, titularidad que proviene de la propia Constitución, que pueden ejercer en las mismas condiciones que los españoles, y a los que, paralelamente, les serán de aplicación las mismas modulaciones o limitaciones.

En consecuencia, la remisión a la ley que contiene el art. 13.1 no supone una desconstitucionalización de la posición jurídica de los extranjeros puesto que el legislador, aún disponiendo de un amplio margen de libertad para concretar los «términos» en los que aquéllos gozarán de los derechos y libertades en España, se encuentra sometido a límites derivados del conjunto del Título I de la Constitución, y

2 Goig Martínez, J. M. Derechos y libertades...Op. cit, pág. 81 
especialmente los contenidos en los apartados primero y segundo del art. 10.

\section{LOS DERECHOS DE LOS INMIGRANTES EN LA LEGISLACIÓN ESPAÑOLA DE EXTRANJERÍA}

Sin entrar en el análisis de la L.O. de 1 de julio, de Derechos y libertades de los extranjeros en España, que regulaba, por primera vez, el ámbito de libertades de los inmigrantes en España, aunque en un contexto cuantitativo y cualitativo totalmente distinto al actual, la L.O 4/2000, de 11 de enero, sobre Derechos y Libertades de los inmigrantes y su integración social, constituyó un intento de equiparar a inmigrantes y españoles no sólo en derechos fundamentales, sino también en los llamados «derechos económicos, sociales y culturales» sin distinguir, salvo para aquellos para los que se exija, al igual que para los españoles, el cumplimiento de determinados requisitos, en virtud de la situación administrativa, favoreciendo la integración social y luchando contra la discriminación.

Sin embargo, su reforma por L.O 8/2000, de 22 de diciembre, afectó a gran parte del articulado, no sólo creando nuevos preceptos y Disposiciones, sino que, principalmente, vino a modificar el espíritu y la intención con que fue aprobada la L.O 4/2000, lo que nos lleva a afirmar que el resultado de esta reforma, es una Nueva Ley de Extranjería. La reforma, que afecta a un $80 \%$ de la Ley, no sólo modifica el régimen de entrada, salida, permanencia y situaciones de los inmigrantes, sino que cambia el reconocimiento de derechos a los extranjeros, retornando a una situación muy parecida a la contemplada por la L.O 7/1985, al recuperar la clara distinción entre los extranjeros dependiendo de su situación administrativa, introduciendo el criterio de residencia legal como elemento otorgativo en el ejercicio de ciertos derechos y libertades a los inmigrantes.

La cuestión se plantea, en consecuencia, en torno a si el legislador ha respetado en esta nueva regulación los mandatos constitucionales y las orientaciones jurisprudenciales sobre la materia.

\section{LA LIBERTAD Y LOS LIMITES DEL LEGISLADOR EN LA JURISPRUDENCIA DEL TRIBUNAL CONSTITUCIONAL}

Al margen del reconocimiento y aceptación de que existen en el Título I derechos cuya titularidad se reserva en exclusiva a los espa- 
ñoles (los reconocidos en el art. $23 \mathrm{CE}$, con la salvedad que contiene), prohibiendo la misma Constitución, con las salvedades contenidas, (art. 13.2 CE) que el legislador los extienda a los extranjeros, como ha indicado el TC, el legislador al que remite el art. 13.1 CE no goza de igual libertad para regular la titularidad y el ejercicio de los distintos derechos del Título I, pues aquélla depende del concreto derecho afectado. Una interpretación sistemática del precepto constitucional impide sostener que los extranjeros gozarán en España sólo de los derechos y libertades que establezcan los tratados y el legislador (SSTC 107/1984), dejando en manos de éste la potestad de decidir qué derechos del Título I les pueden corresponder y cuáles no.

Si existen derechos del Título I que corresponden a los extranjeros por propio mandato constitucional, y no resulta posible un tratamiento desigual respecto de los españoles porque son imprescindibles para la garantía de la dignidad humana que conforme al art. $10.1 \mathrm{de}$ nuestra Constitución es el fundamento del orden político español, la dignidad de la persona, que encabeza el Título I de la Constitución (art. 10.1 CE), constituye un primer límite a la libertad del legislador a la hora de regular ex art. $13 \mathrm{CE}$ los derechos y libertades de los extranjeros en España.

La dignidad de la persona, como «fundamento del orden político y la paz social" (art. 10.1 CE), obliga a reconocer a cualquier persona, independientemente de la situación en que se encuentre, aquellos derechos o contenidos de los mismos imprescindibles para garantizarla, erigiéndose así la dignidad en un mínimo invulnerable que por imperativo constitucional se impone a todos los poderes, incluido el legislador. Proyectada sobre los derechos individuales, la regla del art. 10.1 CE implica que, en cuanto "valor espiritual y moral inherente a la persona" (STC 53/1985) la dignidad ha de permanecer inalterada cualquiera que sea la situación en que la persona se encuentre, constituyendo, en consecuencia un "minimum» invulnerable que todo estatuto jurídico debe asegurar. (STC 91/2000; STC 120/1990; STC 57/1994). De modo que la Constitución española salvaguarda absolutamente aquellos derechos y aquellos contenidos de los derechos «que pertenecen a la persona en cuanto tal y no como ciudadano, aquéllos que son imprescindibles para la garantía de la dignidad humana" (STC 242/1994; STC 99/1985).

El legislador contemplado en el art. $13 \mathrm{CE}$ se encuentra asimismo limitado al regular aquellos derechos que la Constitución reconoce directamente a los extranjeros (STC 115/1987). El legislador no puede negar tales derechos a los extranjeros, aunque sí puede establecer 
"condicionamientos adicionales" respecto a su ejercicio por parte de aquéllos, si bien «ha de respetar, en todo caso, las prescripciones constitucionales, pues no puede estimarse el art. 13.1 CE. permitiendo que el legislador configure libremente el contenido mismo del derecho, cuando éste haya venido reconocido por la Constitución directamente a los extranjeros, pues una cosa es, autorizar diferencias de tratamiento entre españoles y extranjeros, y otra entender esa autorización como una posibilidad de legislar al respecto sin tener en cuenta los mandatos constitucionales" (STC 115/1987). En estos casos, el mandato contenido en el precepto constitucional «constituye en puridad un contenido preceptivo del derecho que se impone al legislador en el momento de regular su ejercicio" por parte de los extranjeros. Para la identificación de estos derechos reconocidos ex constitutione a los extranjeros debe tenerse especialmente en cuenta, entre otros criterios, la dicción de los preceptos del Título I reconocedores de derechos, a los que remite el art. 13.1 CE, pues en ellos se hace normalmente referencia a sus titulares utilizando distintas expresiones ("todos, "todas las personas», «los españoles», "nadie», «los ciudadanos») o también fórmulas impersonales (»se reconoce..», «se garantiza..»).

El legislador goza, en cambio, de mayor libertad al regular los «derechos de los que serán titulares los extranjeros en la medida y condiciones que se establezcan en los Tratados y las Leyes" (STC 107/1984), o dicho de otro modo, de aquellos derechos que no son atribuidos directamente por la Constitución a los extranjeros pero que el legislador puede extender a los no nacionales «aunque no sea necesariamente en idénticos términos que los españoles» (STC 94/1993), puesto que el art. 13.1 CE no dice, que los extranjeros dispongan de los mismos derechos que los españoles, siendo precisamente ese precepto el que, en nuestra Constitución establece los límites subjetivos determinantes de la extensión de la titularidad de los derechos fundamentales a los no nacionales» (Declaración del Tribunal Constitucional de 1 de julio de 1992). Se trata de derechos de los cuales los extranjeros gozarán «en España», presupuesto de la extensión de derechos que lleva a cabo el art. 13.1 CE (STC 72/2005). Al regular tales derechos la libertad del legislador es más amplia ya que puede modular las condiciones de ejercicio «en función de la nacionalidad de las personas, introduciendo tratamientos desiguales entre españoles y extranjeros", si bien aquella libertad "no es en modo alguno absoluta» (STC 94/1993).

Estas afirmaciones jurisprudenciales plantean la dificultad de establecer un criterio para determinar si un concreto derecho pertene- 
ce o no al grupo de derechos que «son imprescindibles para la dignidad humana", puesto que, por su propia naturaleza, todos los derechos estarían vinculados a la dignidad de los seres humanos.

Para ello, el Tribunal indicó algunas pautas para identificar cuáles son esos derechos y esos contenidos de derecho que la Constitución "proyecta universalmente", indicando la necesidad de partir, en cada caso, del tipo abstracto de derecho y de los intereses que básicamente protege, de su contenido esencial, para precisar si, y en qué medi$\mathrm{da}$, son inherentes a la dignidad de la persona humana concebida como un sujeto de derecho, es decir, como miembro libre y responsable de una comunidad jurídica que merezca ese nombre y no como mero objeto del ejercicio de los poderes públicos.» (STC 91/2000), y, precisando aún más, el Tribunal declaró que en este proceso de determinación de tales derechos revisten especial relevancia "la Declaración Universal de Derechos Humanos y los demás tratados y acuerdos internacionales sobre las mismas materias ratificados por España, a los que el art. 10.2 CE remite como criterio interpretativo de los derechos fundamentales. Esa decisión del constituyente expresa el reconocimiento de nuestra coincidencia con el ámbito de valores e intereses que dichos instrumentos protegen, así como nuestra voluntad como Nación de incorporarnos a un orden jurídico internacional que propugna la defensa y protección de los derechos humanos como base fundamental de la organización del Estado.» (STC 91/2000).

Resulta, pues, decisivo el grado de conexión con la dignidad humana que mantiene un concreto derecho dado que el legislador goza de una limitada libertad de configuración al regular los derechos, porque sobre ellos no podrá modular o atemperar su contenido (STC 99/1985) ni por supuesto negar su ejercicio a los extranjeros, cualquiera que sea su situación, ya que se trata de derechos «que pertenecen a la persona en cuanto tal y no como ciudadano".

Todo esto no implica cerrar el paso a las diversas opciones o variantes políticas que caben dentro de la Constitución, entendida como «marco de coincidencias» que permite distintas legislaciones en materia de extranjería. El legislador está facultado, en virtud del art. 13.1 CE para configurar las condiciones de ejercicio de determinados derechos por parte de los extranjeros, teniendo en cuenta la diversidad de estatus jurídico que existe entre los que no gozan de la condición de españoles. El legislador puede tomar en consideración el dato de su situación legal y administrativa en España, y exigir a los extranjeros la autorización de su estancia o residencia como presupuesto 
para el ejercicio de algunos derechos constitucionales que por su propia naturaleza hacen imprescindible el cumplimiento de los requisitos que la misma ley establece para entrar y permanecer en territorio español, opción que no es constitucionalmente ilegítima, como ya ha sido puesto de manifiesto por diversas decisiones del Tribunal Constitucional (SSTC 107/1984; 94/1993, 95/2000). Ahora bien, dicha opción está sometida a los límites constitucionales, puesto que el incumplimiento de los requisitos de estancia o residencia en España por parte de los extranjeros no permite al legislador privarles de los derechos que les corresponden constitucionalmente en su condición de persona, con independencia de su situación administrativa. El incumplimiento de aquellos requisitos legales impide a los extranjeros el ejercicio de determinados derechos o contenidos de los mismos que por su propia naturaleza son incompatibles con la situación de irregularidad, pero no por ello los extranjeros que carecen de la correspondiente autorización de estancia o residencia en España están desposeídos de cualquier derecho mientras se hallan en dicha situación en España.

En definitiva, el art. 13.1 CE concede al legislador cierta libertad para regular los derechos de los extranjeros en España, pudiendo establecer determinadas condiciones para su ejercicio. Sin embargo, una regulación de este tenor deberá tener en cuenta, en primer lugar, el grado de conexión de los concretos derechos con la garantía de la dignidad humana, según los criterios expuestos; en segundo lugar, el contenido preceptivo del derecho, cuando éste venga reconocido a los extranjeros directamente por la Constitución; en tercer lugar, y en todo caso, el contenido delimitado para el derecho por la Constitución y los Tratados Internacionales. A ello, debe añadirse que, las condiciones de ejercicio establecidas por la Ley deberán dirigirse a preservar otros derechos, bienes o intereses constitucionalmente protegidos, y guardar adecuada proporcionalidad con la finalidad perseguida.

\section{EL NUEVO RÉGIMEN DE DERECHOS Y LIBERTADES DE LOS INMIGRANTES EN LA RECIENTE JURISPRUDENCIA DEL TRIBUNAL CONSTITUCIONAL}

El Tribunal Supremo, mediante STS de 20 de marzo de 2003 (Sala de lo Contencioso Administrativo, Sección 6.a) resolvió el primero de un rosario de recursos que pendían sobre la normativa española sobre extranjería. Esta sentencia, recaída en recurso inter- 
puesto contra el RD 864/2001 de 20 de julio de 2001 por el que se aprueba el Reglamento para la ejecución de la Ley Orgánica 4/2000 de 11 de enero de 2000 sobre Derechos y Libertades de los extranjeros en España, reformada por L.O 8/2000 de 22 de diciembre -REODYLE-, ha constituido un elemento importante en aras a corregir determinadas previsiones reglamentarias en materia de extranjería, y modifica ciertas peculiaridades sobre la política de inmigración que ha adoptado el ejecutivo al margen de las previsiones constitucionales y legales, declarando nulos de pleno derecho varios artículos reglamentarios que han sido declarados ilegales ${ }^{3}$, tomando como presupuesto principal y básico de todo Estado de Derecho, la necesidad de que todos los poderes públicos deben de respetar el principio de legalidad reconocido en el art. 9.2 y $9.3 \mathrm{CE}$.

Recientemente, el TC ha tenido ocasión de enjuiciar la constitucionalidad en el tratamiento que la L.O 8/2000 hace, en algunos de sus preceptos, de los derechos y libertades de los inmigrantes, en la resolución de los ocho recursos de inconstitucionalidad que se han interpuesto contra la citada ley.

\section{PRESUPUESTO IMPUGNATORIO}

En el recurso de inconstitucionalidad núm. 1707-2001, interpuesto por el Parlamento de Navarra, contra diversos preceptos de la Ley Orgánica 8/2000, de 22 de diciembre, de reforma de la Ley Orgánica 4/2000, de 11 de enero, sobre Derechos y Libertades de los Extranjeros en España y su Integración Social, resuelto por STC 236/2007, de siete de noviembre, el TC resuelve, por primera vez la posible inconstitucionalidad de una ley que niega el ejercicio de determinados derechos no a los extranjeros en general, sino a aquéllos que no dispongan de la correspondiente autorización de estancia o residencia en España.

La cuestión a la que se enfrenta el TC parte de la consideración de si la Constitución no distingue entre los extranjeros en función de la regularidad de su estancia o residencia en España, podría resultar constitucional que el legislador atienda a esa diferencia para configurar la situación jurídica de los extranjeros siempre que al hacerlo no vulnere preceptos o principios constitucionales.

${ }^{3}$ Un amplio comentario a la STS de 20 de marzo de 2003 puede verse en Goig Martínez, J. M. «Régimen jurídico y políticas sobre extranjería en España. Comentario a la STS de 20 de marzo de 2003", Teoría y Realidad Constitucional, núm. 12-13, $2 .^{\circ}$ semestre 2003-1. ${ }^{\circ}$ semestre 2004, UNED, pp. 631-654. 
En base a esta cuestión, el TC se plantea en la STC 236/2007, de 7 de noviembre el enjuiciamiento de los preceptos de la L.O 8/2000 impugnados en el recurso, al objeto de dar respuesta a los concretos normativos de inconstitucionalidad alegados por la entidad recurrente frente a cada uno de ellos, y lo hace bajo dos premisas previas:

1. El juicio de constitucionalidad que debe realizar en el presente proceso no consiste en examinar si en el marco constitucional cabrían otras opciones en materia de extranjería distintas a la adoptada por la Ley Orgánica 8/2000, de 22 de diciembre, sino en determinar si los preceptos de esa Ley sometidos a su enjuiciamiento han excedido o no los límites impuestos por la Constitución.

2. Al enjuiciar la Ley impugnada en este proceso, corresponde determinar si el legislador ha respetado los límites impuestos ex art. 10.2 CE por las normas internacionales, que le obligan a interpretar de acuerdo con ellas los derechos y libertades consagrados en nuestra Constitución. Las normas legales impugnadas deben ser contrastadas con los correspondientes preceptos constitucionales que proclaman los derechos y libertades de los extranjeros en España, interpretados de acuerdo con el contenido de dichos Tratados o Convenios. En consecuencia, sólo podrá declararse su inconstitucionalidad si aquellas normas con rango de ley vulneran el contenido constitucionalmente declarado de tales derechos y libertades.

Como indica el TC, en base a jurisprudencia anterior ${ }^{4}$, el legislador español, al regular los derechos de los extranjeros, resulta limitado ex art. 10.2 CE por los Tratados Internacionales ratificados por España.

${ }^{4} \mathrm{El} \mathrm{TC}$ ha afirmado en reiteradas ocasiones la utilidad de los textos internacionales ratificados por España "para configurar el sentido y alcance de de los derechos fundamentales, de conformidad con lo establecido en el art. 10.2 CE" (SSTC 38/1981; 84/1989). En concreto, en la STC 64/1991, ha explicado el significado de la «interpretación" a la que alude el art. 10.2 CE señalando que "no convierte a tales tratados y acuerdos internacionales en canon autónomo de validez de las normas y actos de los poderes públicos desde la perspectiva de los derechos fundamentales. Si así fuera, sobraría la proclamación constitucional de tales derechos, bastando con que el constituyente hubiera efectuado una remisión a las Declaraciones internacionales de derechos humanos o, en general, a los tratados que suscriba al Estado español sobre derechos fundamentales y libertades públicas. Por el contrario, realizada la mencionada proclamación, no puede haber duda de que la validez de las disposiciones y actos impugnados en amparo debe medirse sólo por referencia a los preceptos constitucionales que reconocen los derechos y libertades susceptibles de protección en esta clase de litigios, siendo los textos y acuerdos internacionales del art. 10.2 una 
$\mathrm{El}$ art. $13 \mathrm{CE}$ autoriza al legislador a establecer restricciones y limitaciones a los derechos de los extranjeros en España, pero sin afectar «al contenido delimitado para el derecho por (..) los Tratados Internacionales» (STC 242/1994), que debe observar para configurar el sentido y alcance de los derechos fundamentales. Como cualquier otro poder público, también el legislador está obligado a interpretar los correspondientes preceptos constitucionales de acuerdo con el contenido de dichos Tratados o Convenios, que se convierte así en el "contenido constitucionalmente declarado" de los derechos y libertades que enuncia el Capítulo segundo del Título I de nuestra Constitución (STC 236/2007).

Por consiguiente, al enjuiciar la Ley impugnada en este proceso, le corresponde al TC, determinar si el legislador ha respetado los límites impuestos ex art. 10.2 CE por las normas internacionales, que le obligan a interpretar de acuerdo con ellas los derechos y libertades consagrados en nuestra Constitución. El tratado o convenio internacional invocado no se convierte en sí mismo en canon de constitucionalidad de los concretos preceptos recurridos, como pretende el Parlamento, pero las normas legales impugnadas deben ser contrastadas con los correspondientes preceptos constitucionales que proclaman los derechos y libertades de los extranjeros en España, interpretados de acuerdo con el contenido de dichos Tratados o Convenios, aunque sólo podrá declararse su inconstitucionalidad si

fuente interpretativa que contribuye a la mejor identificación del contenido de los derechos cuya tutela se pide a este Tribunal Constitucional».

Por otra parte, en STC 36/1991 se ha pronunciado sobre la vinculación del legislador al art. 10.2 CE y su posible control a través de los procedimientos de declaración de inconstitucionalidad. Así ha negado la posibilidad de que un precepto legal pueda infringir autónomamente el art. 10.2 CE, declarando que "esta norma se limita a establecer una conexión entre nuestro propio sistema de derechos fundamentales y libertades, de un lado, y los Convenios y Tratados internacionales sobre las mismas materias en los que sea parte España, de otro. No da rango constitucional a los derechos y libertades internacionalmente proclamados en cuanto no estén también consagrados por nuestra propia Constitución, pero obliga a interpretar los correspondientes preceptos de ésta de acuerdo con el contenido de dichos Tratados o Convenios, de modo que en la práctica este contenido se convierte en cierto modo en el contenido constitucionalmente declarado de los derechos y libertades que enuncia el capítulo segundo del título I de nuestra Constitución. Es evidente, no obstante, que cuando el legislador o cualquier otro poder público adopta decisiones que, en relación con uno de los derechos fundamentales o las libertades que la Constitución enmarca, limita o reduce el contenido que al mismo atribuyen los citados Tratados o Convenios, el precepto constitucional directamente infringido será el que enuncia ese derecho o libertad, sin que a ello añada nada la violación indirecta y mediata del art. 10.2 CE, que por definición no puede ser nunca autónoma, sino dependiente de otra, que es la que este Tribunal habrá de apreciar en su caso.» 
las normas con rango de ley vulneran el contenido constitucionalmente declarado de tales derechos y libertades.

Los criterios fundamentales reconocidos por el TC en la STC 236/2007, de 7 de noviembre, que parten de sus premisas de actuación, han sido ratificados por el resto de Sentencias dictadas por el TC a la hora de enjuiciar la constitucionalidad de la L.O 4/2000, en su versión dada por la L.O 8/2000: STC 259/2007, de 19 de diciembre de 20075; STC 260/2007, de 20 de diciembre de 20076; STC 261/2007, de 20 de diciembre de 20077; STC 262/2007, de 20 de diciembre de $2007^{8}$; STC 263/2007, de 20 de diciembre de 20079; STC 264/2007, de 20 de diciembre de $2007^{10}$, y STC 265/2007, de 20 de diciembre de $2007^{11}$.

${ }^{5}$ En el recurso de inconstitucionalidad núm. 1640-2001, interpuesto por el Consejo de Gobierno de la Junta de Andalucía contra el artículo 1, apartados 5, 6, 9, 15, 16 y 56 de la Ley Orgánica 8/2000, de 22 de diciembre, de reforma de la Ley Orgánica 4/2000, de 11 de enero, sobre derechos y libertades de los extranjeros en España y su integración social.

- En el recurso de inconstitucionalidad núm. 1644-2001, interpuesto por el Parlamento Vasco contra el artículo 1, apartados $5,6,9,12,13,50,54,55$ y 56 de la Ley Orgánica 8/2000, de 22 de diciembre, de reforma de la Ley Orgánica 4/2000, de 11 de enero, sobre derechos y libertades de los extranjeros en España y su integración social.

7 En el recurso de inconstitucionalidad núm. 1668-2001, interpuesto por sesenta y cuatro Diputados del Grupo Parlamentario del PSOE en el Congreso contra el artículo 1, apartados 5, 6, 9, y 16 de la Ley Orgánica 8/2000, de 22 de diciembre, de reforma de la Ley Orgánica 4/2000, de 11 de enero, sobre derechos y libertades de los extranjeros en España y su integración social.

${ }_{8}$ En el recurso de inconstitucionalidad núm. 1669-2001, interpuesto por el Consejo de Gobierno de la Junta de Comunidades de Castilla-La Mancha contra el artículo. 1, apartados $5,6,7,9,15,16,50,56$ y 57 de la Ley Orgánica 8/2000, de 22 de diciembre, de reforma de la Ley Orgánica 4/2000, de 11 de enero, sobre derechos y libertades de los extranjeros en España y su integración social.

${ }^{9}$ En el recurso de inconstitucionalidad núm. 1671-2001, interpuesto por la Diputación General de Aragón contra el artículo 1, apartados 5, 6, 9 y 16 de la Ley Orgánica 8/2000, de 22 de diciembre, de reforma de la Ley Orgánica 4/2000, de 11 de enero, sobre derechos y libertades de los extranjeros en España y su integración social.

10 En el recurso de inconstitucionalidad núm. 1677-2001, interpuesto por el Consejo de Gobierno de la Junta de Extremadura contra el artículo 1, apartados 5, 6, 9 y 16 de la Ley Orgánica 8/2000, de 22 de diciembre, de reforma de la Ley Orgánica 4/2000, de 11 de enero, sobre derechos y libertades de los extranjeros en España y su integración social.

${ }_{11}$ En el recurso de inconstitucionalidad núm. 1679-2001, interpuesto por el Consejo de Gobiemo del Principado de Asturias contra el artículo 1, apartados 5, 6, 9 y 16 de la Ley Orgánica 8/2000, de 22 de diciembre, de reforma de la Ley Orgánica 4/2000, de 11 de enero, sobre derechos y libertades de los extranjeros en España y su integración social. 
Como hemos indicado anteriormente, la posición del legislador, al regular los derechos y libertades, se encuentra especialmente sometida e impregnada por la propia Constitución y por el espíritu constitucional que la rodea, de forma tal que a la hora de regular un derecho o una libertad deberá tener en cuenta el contenido constitucionalmente declarado, pero además, deberá aceptar las exigencias derivadas de la definición del Estado español como Estado social y democrático de Derecho (art. 1.1); los valores superiores del ordenamiento jurídico, y las facultades que de ellos se derivan; deberá tomar en consideración, por mandato del art. 10.2, la Declaración Universal de Derechos Humanos y los Tratados y Acuerdos Internacionales ratificados por España en materia de derechos y libertades, sin olvidar que forman parte del ordenamiento interno, y, especialmente por su sometimiento a la Constitución (art. 9.1) y por su vinculación a los derechos y libertades (art. 53.1) deberá tener en cuenta la especial relación de la dignidad de la persona con los derechos.

La interpretación del alcance y contenido de los derechos y libertades «ha de hacerse considerando la Constitución como un todo en el que cada precepto encentra su sentido pleno valorándolo en relación con los demás, es decir, de acuerdo con una interpretación sistemática» (STC 5/1983), y el carácter excepcional con que deberá considerarse toda acción que limite o restrinja un derecho o una liberad reconocida constitucionalmente, implica que ésta deberá hacerse sólo por ley, que deberá respetar el contenido esencial del derecho, pero, además, deberá estar motivada y justificada, y deberá ser proporcional al fin perseguido (STC 13/1985).

\section{CONTENIDO DE LAS RESOLUCIONES}

Como afirmábamos al inicio de este estudio, la importancia de la STC 236/2007, de 7 de noviembre, y de las otras dictadas en recursos de inconstitucionalidad presentados contra la L.O 4/2000 en su versión dada por la L.O 8/2000, radica, principalmente, en constituir la primera vez en que el TC resuelve sobre la posible inconstitucionalidad de una ley que, reconociendo la titularidad de determinados derechos y libertades a los extranjeros, niega el ejercicio de estos derechos, no a los extranjeros en general, sino solamente a aquellos que no dispongan de la autorización de estancia o residencia, exigida por la legislación de extranjería.

Además, del análisis de la fundamentación jurídica que realiza el TC, se fija de manera clara la posición del legislador a la hora de proceder a una regulación de esta naturaleza. 
En palabras del TC. :

1. El legislador contemplado en el art. $13 \mathrm{CE}$ se encuentra limitado al regular aquellos derechos que, «la Constitución reconoce directamente a los extranjeros» (STC 115/1987, de 7 de julio, FJ 2).

2. El legislador no puede negar tales derechos a los extranjeros, aunque sí puede establecer «condicionamientos adicionales» respecto a su ejercicio por parte de aquéllos, si bien «ha de respetar, en todo caso, las prescripciones constitucionales, pues no puede estimarse el art. 13.1 CE. permitiendo que el legislador configure libremente el contenido mismo del derecho, cuando éste haya venido reconocido por la Constitución directamente a los extranjeros. (..). Una cosa es, en efecto, autorizar diferencias de tratamiento entre españoles y extranjeros, y otra entender esa autorización como una posibilidad de legislar al respecto sin tener en cuenta los mandatos constitucionales».

3. El mandato contenido en el precepto constitucional «constituye en puridad un contenido preceptivo del derecho que se impone al legislador en el momento de regular su ejercicio" por parte de los extranjeros. Para la identificación de estos derechos reconocidos ex constitutione a los extranjeros debe tenerse especialmente en cuenta, entre otros criterios, la dicción de los preceptos del Título I reconocedores de derechos, a los que remite el art. 13.1 CE, pues en ellos se hace normalmente referencia a sus titulares utilizando distintas expresiones ("todos, «todas las personas», «los españoles», "nadie», «los ciudadanos») o también fórmulas impersonales ("se reconoce..», "se garantiza..»).El legislador se encuentra, por consiguiente, limitado a la hora de regular aquellos derechos y libertades que la Constitución reconoce indistintamente a españoles y extranjeros, y a éstos sin distinguir por su situación administrativa.

4. El legislador goza, en cambio, de mayor libertad al regular los aquellos derechos que no son atribuidos directamente por la Constitución a los extranjeros pero que el legislador puede extender a los no nacionales "aunque no sea necesariamente en idénticos términos que los españoles» (STC 94/1993, FJ 3) porque el art. 13.1 CE no dice, en efecto, que los extranjeros dispongan de los mismos derechos que los españoles, siendo precisamente ese precepto el que «en nuestra Constitución 
establece los límites subjetivos determinantes de la extensión de la titularidad de los derechos fundamentales a los no nacionales» [Declaración del Tribunal Constitucional de 1 de julio de 1992, FJ 3 b)]. Si bien aquella libertad «no es en modo alguno absoluta» (STC 94/1993, de 22 de marzo, FJ 3).

5. También el legislador se encuentra limitado por la regulación que sobre estos derechos y libertades realizan los Tratados y Convenios Internacionales sobre la materia, por constituir elemento interpretativo determinante de su alcance.

6. Cuando los preceptos legales no se limitan a condicionar el ejercicio de derechos y libertades por parte de los extranjeros en situación irregular, sino que impiden su ejercicio de manera radical, se está negando el derecho o libertad (STC 236/2007, de 7 de noviembre)

Se alinea en este último punto el TC con un importante sector de la doctrina ${ }^{12}$, que ha manifestado que reconocer la titularidad de un derecho y no su ejercicio equivale a negar este derecho. Privar a los extranjeros en situación irregular de los derechos fundamentales de asociación, reunión y manifestación, no sólo rompe el propio sistema de derechos, sino que se convierte en una agresión potencial para los derechos de todos los ciudadanos.

A través de los distintos recursos de inconstitucionalidad planteados, se recurre la inconstitucionalidad de los preceptos de la L.O. $8 / 2000$, que dan nueva redacción a los artículos de la L.O. 4/2000 que regulan el derecho de reunión y manifestación (art. 7); el derecho de asociación (art. 8); el derecho a la educación (art. 9.3); el derecho de sindicación (art. 11.1); el derecho a la huelga (art. 11.2); el derecho a la tutela judicial efectiva (art. 22.2) y otros preceptos de la ley, que serán examinados, por considerar que vulneran los artículos $17 ; 18 ; 19$; $21 ; 22 ; 24 ; 25 ; 27$ y 29 de la Constitución en su interpretación por los Tratados y Convenios Internacionales sobre la materia ratificados por España.

En las distintas resoluciones, el TC, al estimar parcialmente los recursos, ha adoptado los siguientes criterios:

1. El TC, en STC 236/2007, declara inconstitucional y nula la inclusión del término "residentes» en los arts. 9.3( derecho a la

12 Entre otros, Aragón Reyes, M; Asensi Sabater; J; Biglinio Campos, P, o Carrillo, $\mathbf{M}$, en sus respuestas a la encuesta que plantea el n. ${ }^{\circ} 7$ de la Revista Teoría y Realidad Constitucional, 2001 


\section{educación) y 22.2 (asistencia jurídica gratuita) de la Ley Orgá- nica 4/2000, de 11 de enero, en la redacción dada por la Ley Or- gánica 8/2000, de 22 de diciembre: ${ }^{13}$}

Respecto al derecho a la educación, la CE atribuye genéricamente a "todos «el derecho a la educación, por considerar que como derecho del ser humano debe ser abarcado con la mayor generosidad. Además, tiene por objeto: el pleno desarrollo de la personalidad; la formación en el respeto de los derechos y libertades fundamentales y en el ejercicio de la tolerancia y la libertad dentro de los principios democráticos de convivencia; la preparación para participar activamente en la vida social y cultural y la formación para la paz, la cooperación y la solidaridad entre pueblos (art. 2 L.O.E; art. 1.1 LOGSE; art. 26.2 DUDH y art. 13 PIDESC). La reforma planteada por la L.O. $8 / 2000$ supone un grave retroceso e importantes límites para el acceso a la educación de los extranjeros.

Como indica el TC en la STC 236/2007, al examinar los Tratados Internacionales sobre la materia: «De las disposiciones transcritas se deduce la inequívoca vinculación del derecho a la educación con la garantía de la dignidad humana, dada la innegable trascendencia que aquélla adquiere para el pleno y libre desarrollo de la personalidad, y para la misma convivencia en sociedad, que se ve reforzada mediante la enseñanza de los valores democráticos y el respeto a los derechos humanos, necesarios para "establecer una sociedad democrática avanzada", como reza el Preámbulo de nuestra Constitución".

De las disposiciones constitucionales relativas al derecho a la educación, interpretadas de conformidad con la Declaración Universal de Derechos Humanos y los Tratados y acuerdos internacionales referidos, se deduce que el contenido constitucionalmente garantizado de

13 Esta declaración se hace en la STC 236/2007, de 7 de noviembre. En el resto de sentencias, como indica la Sentencia de referencia: La referida declaración de inconstitucionalidad y nulidad (...), determina la pérdida sobrevenida del objeto de esta concreta impugnación, ya que «siendo el efecto inmediato de la anulación de cualquier norma su expulsión del ordenamiento jurídico de una vez por todas y para siempre, medida irreversible por su propia naturaleza, la pretensión que se ejercita aquí y ahora resulta ya redundante y vacía de contenido, sin finalidad práctica alguna. En definitiva, una vez que nuestras Sentencias dejan si efecto uno o varios preceptos legales, cualquier otro proceso paralelo o posterior queda desprovisto automáticamente de su propio objeto. Una disposición sólo puede extinguirse una sola vez, por definición ... Tal desaparición sobrevenida del elemento objetivo del proceso impide cualquier consideración sobre lo que en el lenguaje forense ha dado en llamarse el fondo del asunto" (STC 166/1994, de 26 de mayo, FJ 2; ATC 267/2002, de 10 de diciembre, FJ 2). 
ese derecho, en su dimensión prestacional, no se limita a la enseñanza básica, sino que se extiende también a los niveles superiores, aunque en ellos no se imponga constitucionalmente la obligatoriedad y la gratuidad. Por otra parte, también de las disposiciones examinadas y de su recta interpretación se obtiene que el derecho a la educación garantizado en el art. 27.1 CE corresponde a «todos", independientemente de su condición de nacional o extranjero, e incluso de su situación legal en España. Esta conclusión se alcanza interpretando la expresión del art. 27.1 CE de acuerdo con los textos internacionales citados, donde se utilizan las expresiones «toda persona tiene...», o «a nadie se le puede negar...» el derecho a la educación. Según se ha visto, el acceso a los establecimientos escolares y el derecho a utilizar, en principio, los medios de instrucción que existan en un momento determinado, debe garantizarse, de acuerdo con el art. 1 CEHD, «a toda persona dependiente de la jurisdicción de un Estado contratante». Esta expresión contenida en el art. $1 \mathrm{CEDH}$, interpretada conjuntamente con el art. $14 \mathrm{CEDH}$ (Caso Irlanda contra Reino Unido, de 18 de enero de 1978, § 238; Caso Príncipe Hans-Adams II de Lichtenstein, de 12 de julio de 2001, § 46), debe entenderse que incluye también a aquellas personas no nacionales que se encuentren en una situación irregular o ilegal.

Concluye el TC que: «El contenido constitucionalmente declarado por los textos a los que se refiere el art. 10.1 CE del derecho a la educación garantizado en el art. 27.1 CE incluye el acceso no sólo a la enseñanza básica, sino también a la enseñanza no obligatoria, de la que no pueden ser privados los extranjeros que se encuentren en España y no sean titulares de una autorización para residir. El precepto impugnado impide a los extranjeros menores de dieciocho años sin autorización de estancia o residencia acceder a la enseñanza secundaria postobligatoria, a la que sin embargo pueden acceder, según la legislación educativa vigente, aquellos que hayan obtenido el título de Graduado en Educación Secundaria Obligatoria, normalmente a la edad de dieciséis años. Ese derecho de acceso a la educación no obligatoria de los extranjeros menores de edad forma parte del contenido del derecho a la educación, y su ejercicio puede someterse a los requisitos de mérito y capacidad, pero no a otra circunstancia como la situación administrativa del menor».

Declara el TC inconstitucional y nula la regulación que la L.O. $8 / 2000$ hace del derecho a la asistencia jurídica gratuita.

Con base en la STC 95/2003 por la que se resuelve recurso de inconstitucionalidad planteado por el Defensor del Pueblo contra el in- 
ciso "que residan legalmente en España», contenido en el art. 2 de la Ley 1/1996, de 10 de enero, de asistencia jurídica gratuita (LAJG), partiendo de «la conexión instrumental entre el derecho a la asistencia jurídica gratuita y el derecho a la tutela judicial efectiva», y reiterando la titularidad del derecho a la tutela judicial efectiva por parte de los extranjeros, "con independencia de su situación jurídica», concluye que la norma impugnada está viciada de inconstitucionalidad por entrañar «una vulneración del derecho a la tutela judicial efectiva consagrado en el art. 24.1 CE, del que, como se dijo, son titulares todas las personas (también los extranjeros no residentes legalmente en España)». Es más, al precisar el alcance de la declaración de inconstitucionalidad del art. 2 LAJG, la Sentencia puntualiza que: "Al apreciarse inconstitucionalidad en la exigencia del requisito de la legalidad de la residencia, los extranjeros que se encuentren en España y reúnan las condiciones requeridas legalmente para ello podrán acceder a la asistencia jurídica gratuita en relación con cualquier tipo de proceso a efectos del cual gocen de la precisa legitimación.».

La aplicación de esta jurisprudencia al enjuiciamiento del art. 22.2 de la Ley Orgánica 4/2000, modificado por la Ley aquí impugnada, lleva directamente a apreciar su inconstitucionalidad. En efecto, como indica el TC, el apartado 1 del art. 22 concede a «los extranjeros que se hallen en España y carezcan de recursos económicos suficientes (..)» el derecho a la asistencia jurídica gratuita «en los procedimientos administrativos o judiciales que puedan llevar a la denegación de su entrada, a su devolución o expulsión del territorio español y en todos los procedimientos en materia de asilo». Por su parte, el apartado 2 del art. 22, aquí impugnado, reserva a los «extranjeros residentes» el derecho a la asistencia jurídica gratuita «en iguales condiciones que los españoles en los procesos en los que sean parte, cualquiera que sea la jurisdicción en la que se sigan». Ello supone la exigencia del requisito de la legalidad de la residencia para que los extranjeros puedan acceder a la asistencia jurídica gratuita en relación con cualquier tipo de proceso a efectos del cual gocen de la precisa legitimación, lo cual resulta inconstitucional (STC 236/2007, de 7 de noviembre)

2. Declara la inconstitucionalidad y nulidad del inciso «cuando estén autorizados a trabajar» del art. 11.2 (derecho a la huelga) de la Ley Orgánica 4/2000, de 11 de enero, en la redacción dada por la Ley Orgánica 8/2000, de 22 de diciembre.

Como indica el TC; "la exclusión total del derecho de huelga de aquellos extranjeros que trabajen a pesar de carecer de la corres- 
pondiente autorización administrativa para ello - la cual, por lo demás, no están personalmente obligados a solicitar - no se compadece con el reconocimiento del derecho de huelga que proclama el art. 28.2 CE, interpretado conforme a la normativa internacional sobre este derecho ratificada por España, en particular el art. 8.1 d) PIDESC, en cuya virtud los Estados signatarios del Pacto han de garantizar el ejercicio del derecho de huelga, de forma que la regulación que se establezca deberá tener por objeto el ejercicio del derecho y no impedirlo a los trabajadores que prestan servicios retribuidos por cuenta ajena sin contar con los preceptivos permisos legales".

"La concepción criticada no se corresponde con la titularidad del derecho fundamental ejercitable en la defensa de los intereses de los trabajadores, entre los que puede encontrarse la consecución de la plena regularidad de su situación administrativa. De ahí que no resulte absurdo (...), reconocer este concreto derecho a los extranjeros no autorizados administrativamente para trabajar en España, quienes pueden ejercerlo para la defensa de sus intereses, entre los que puede encontrarse la regularidad de su situación, pese a la irregularidad de la misma. De esta forma la norma aquí controvertida no garantiza la debida protección de los intereses que, a través del reconocimiento constitucional del derecho de huelga, se tratan de satisfacer". (STC 259/2007, de 19 de diciembre de 2007)

3. Declara la inconstitucionalidad, de los arts. 7.1 (derecho de reunión), 8 (derecho de asociación) y 11.1 (exclusivamente respecto al derecho a sindicarse libremente) de la Ley Orgánica 4/2000, de 11 de enero, en la redacción dada por la Ley Orgánica 8/2000, de 22 de diciembre, pero no su nulidad.

En relación al tratamiento que la L.O 8/2000 hace de los derechos de reunión y manifestación, aunque el precepto enjuiciado establece una equiparación entre españoles y extranjeros en cuanto a la titularidad y el ejercicio del derecho de reunión, exigiendo sin embargo un requisito para los segundos, a saber, que éstos hayan obtenido la autorización de estancia o residencia en España, lo que podría entenderse que se trata de uno de los "condicionamientos adicionales» que, como se ha dicho, el legislador puede legítimamente establecer al ejercicio de un derecho que «la Constitución reconoce directamente a los extranjeros», como indica el TC: «el precepto debatido no se limita a condicionar el ejercicio del derecho de reunión por parte de los extranjeros en situación irregular sino que impide radicalmente cualquier ejercicio del mismo a las personas que se encuentren en España en aquella situación." 
En suma, para el TC: «...la definición constitucional del derecho de reunión realizada por nuestra jurisprudencia, y su vinculación con la dignidad de la persona, derivada de los textos internacionales, imponen al legislador el reconocimiento de un contenido mínimo de aquel derecho a la persona en cuanto tal, cualquiera que sea la situación en que se encuentre. En este sentido, ya hemos declarado que «'el ejercicio del derecho de reunión y de manifestación forma parte de aquellos derechos que, según el art. 10 de la norma fundamental, son el fundamento del orden político y de la paz social', por lo que 'el principio de libertad del que es una manifestación exige que las limitaciones que a él se establezcan respondan a supuestos derivados de la Constitución y que en cada caso resulte indubitablemente probado que se ha traspasado efectivamente el ámbito de libertad constitucional fijado' (STC 101/1985).» (STC 59/1990). El legislador orgánico puede fijar condiciones específicas para el ejercicio del derecho de reunión por parte de los extranjeros que se encuentran en nuestro país sin la correspondiente autorización de estancia o residencia, siempre y cuando respete un contenido del mismo que la Constitución salvaguarda por pertenecer a cualquier persona, independientemente de la situación en que se encuentre.

La nueva redacción dada por el precepto impugnado al art. 7.1 de la Ley Orgánica 4/2000 no realiza una modulación del derecho de reunión, estableciendo condiciones a su ejercicio, sino que niega este derecho a los extranjeros que no dispongan de autorización de estancia o residencia en España».(STC 236/2007, de 7 de noviembre)

La declaración de inconstitucionalidad del art. 8 de la L.O 4/2000 en la redacción que le da el art. 1, punto 6, de la L.O. 8/2000, regulador del derecho de asociación, lo basa el TC en que se trata de un derecho que «se encuentra vinculado a la dignidad humana y al libre desarrollo de la personalidad por cuanto protege el valor de la sociabilidad como dimensión esencial de la persona y en cuanto elemento necesario para la comunicación pública en una sociedad democrática. Dado que se trata de un derecho cuyo contenido está unido a esa dimensión esencial, la Constitución y los tratados internacionales lo "proyectan universalmente» y de ahí que no sea constitucionalmente admisible la negación de su ejercicio a los extranjeros que carezcan de la correspondiente autorización de estancia o residencia en España. Ello no significa, como ya hemos dicho respecto del derecho de reunión, que se trate de un derecho absoluto, y por ello el legislador puede establecer límites a su ejercicio por parte de cualquier persona, siempre que respete su contenido constitucionalmente declarado", lo que conduce «a la conclusión de que la nueva redacción dada al art. 8 
de la Ley Orgánica 4/2000 por el art. 1, punto 6, de la Ley impugnada, al excluir cualquier ejercicio de este derecho por parte de los extranjeros que carecen de autorización de estancia o residencia en España ha vulnerado el art. $22 \mathrm{CE}$ en su contenido constitucionalmente declarado por los textos a los que se refiere el art. 10.2 CE.» (STC 236/2007, de 7 de noviembre).

También declara el TC la inconstitucionalidad del art. 11.1 de la Ley Orgánica 4/2000, de 11 de enero, regulador del derecho de sindicación en la redacción dada por el art. 1, punto 9, de la Ley Orgánica 8/2000, de 22 de diciembre, por ser contrario al art. 28.1 CE. (STC 236/2007, de 7 de noviembre). La jurisprudencia del TC ha vinculado «...la titularidad del derecho de libertad sindical a «todos" los trabajadores en su caracterización material, y no jurídico-formal, y a "todos" los sindicatos (art. 28.1 en relación con el art. 7 $\mathrm{CE}$ ), entendiendo de este modo la proyección universal subjetiva que de dicho derecho efectúan los tratados internacionales. «(...)La concepción según la cual el derecho de libertad sindical se ejercería exclusivamente por quienes ostentan la condición de trabajador en sentido legal, es decir, por quienes «sean sujetos de una relación laboral» (en los términos del art. 1.2 LOLS), no se corresponde con la titularidad del derecho fundamental, ejercitable, entre otras finalidades posibles en la defensa de los intereses de los trabajadores, para llegar a ostentar tal condición jurídico-formal. De ahí que no resulte absurdo, como alega el Abogado del Estado, reconocer este concreto derecho a los extranjeros no autorizados para estar o residir en España, quienes pueden afiliarse a los Sindicatos españoles para la defensa de sus intereses, entre los que puede encontrarse la regularidad de su situación, pese a la irregularidad de la misma» (STC 236/2007). Aunque también aquí precisa el TC, que el legislador orgánico puede fijar condiciones específicas para el ejercicio del derecho de sindicación por parte de los extranjeros que se encuentran en nuestro país sin la correspondiente autorización de estancia o residencia, siempre y cuando respete un contenido del mismo que la Constitución salvaguarda por pertenecer a cualquier persona, independientemente de la situación en que se encuentre.

Estos razonamientos anteriores conducen a la inconstitucionalidad del art. 11.1 de la Ley Orgánica 4/2000, de 11 de enero, en la redacción dada por el art. 1, punto 9, de la Ley Orgánica 8/2000, de 22 de diciembre, por ser contrario al art. 28.1 CE. (STC 236/2007, de 7 de noviembre), sin embargo, la inconstitucionalidad de ese inciso viene referida exclusivamente al derecho a sindicarse libremente, con los efectos que se expondrán en el último apartado de este estudio. 


\section{Desestima los recursos en todo las demás pretensiones.}

Junto a la regulación legislativa declarada inconstitucional por las sentencias en comentario, las entidades recurrentes consideraron, en su momento, que la regulación de determinados preceptos legislativos podrían vulnerar los artículos 17; 18; 19; 24 y 25 de la Constitución, pretensiones que han sido desestimadas.

Las desestimaciones de estas pretensiones de inconstitucionalidad planteadas, pueden ser sistematizadas de la siguiente manera:

1. Impugna el Parlamento de Navarra los puntos 12 y 13 del artículo primero de la Ley 8/2000, que dan nueva redacción a los arts. $16.2,17.2$ de la Ley Orgánica 4/2000, y añaden un nuevo art. 18, todos relativos a la intimidad familiar y al reagrupamiento familiar, por la remisión «en blanco» que los citados preceptos hacen a los reglamentos para su posterior desarrollo - reglamentariamente se determinará el tiempo de convivencia en España que tenga que ser acreditada (art. 16); las condiciones para el ejercicio del derecho de reagrupación, en especial, del que corresponda a quienes hayan adquirido la residencia en virtud de una previa reagrupación (art. 17 y 18)-, que se reputa contraria a la reserva de Ley Orgánica del art. 81.1 $\mathrm{CE}$, o alternativamente, la reserva de ley del art. 53.1 CE por afectar al contenido y límites del derecho a la intimidad (art. 18.1 CE), y por incumplir las exigencias constitucionales de tales remisiones.

Sin embargo, esta pretendida inconstitucionalidad, se basa en una idea desacertada de la naturaleza de la reagrupación familiar, que podría concebirse como un desarrollo del derecho a la intimidad familiar (art. 18.1 CE), y, por consiguiente, se debería atribuir «rango" de Ley Orgánica a los arts. 16, 17 y 18 de la Ley recurrida (disposición final primera), sin embargo, la naturaleza de la reagrupación familiar contenida en los citados artículos debería concebirse como una modalidad de protección jurídica de la familia contenida en el art. 39.1 CE, que se limita a establecer un mandato respecto del cual no opera ninguna reserva constitucional, y no como una derivación del derecho a la intimidad familiar.

$\mathrm{Y}$ este es el criterio asumido por el TC, al considerar que la denunciada inconstitucionalidad de las remisiones reglamentarias sólo puede apreciarse si previamente se comprueba que los preceptos recurridos versan sobre el derecho fundamental a la intimidad consagrado en el art. 18.1 CE, el cual es objeto de las reservas de ley establecidas en los arts. 81.1 y 53.1 CE, presuntamente infringidos. Y ello porque los preceptos recurridos sólo podrían reputarse contrarios a la 
Constitución si realizaran efectivamente una remisión reglamentaria en blanco para desarrollar las condiciones de ejercicio del derecho fundamental a la intimidad familiar (art. 18.1 CE). Este derecho a la reagrupación familiar, no forma parte del contenido del derecho consagrado en el art. $18 \mathrm{CE}$, que regula la intimidad familiar como una dimensión adicional de la intimidad personal, y así lo ha reconocido nuestra jurisprudencia (STC 231/1988, de 2 de diciembre, FJ 3).

Como ha indicado el TC, «Nuestra Constitución no reconoce un «derecho a la vida familiar» en los mismos términos en que la jurisprudencia del TEDH ha interpretado el art. 8.1 CEDH, y menos aún un derecho fundamental a la reagrupación familiar, pues ninguno de dichos derechos forma parte del contenido del derecho a la intimidad familiar garantizado por el art. 18.1 CE. La reagrupación familiar, regulada en los preceptos impugnados, puede constituir una modalidad de protección de la familia, haciendo efectivo el principio rector consagrado en el art. 39.1 CE, pero no es un derecho fundamental reconocido constitucionalmente, ni puede ser extraído, por interpretación extensiva, de ninguno de los derechos fundamentales que la Norma Suprema reconoce, siendo preciso, en este punto, recordar que los «derechos fundamentales y libertades públicas» cuyo desarrollo exige ser regulado mediante Ley Orgánica, de acuerdo con el art. 81.1 CE, son exclusivamente los comprendidos en la sección primera, capítulo segundo, título I de la Constitución (arts. 15 a 29)» (STC 236/2007).

2. También, se impugnan el punto $14 \mathrm{del}$ artículo primero de la Ley Orgánica 8/2000, que da nueva redacción al inciso final del apartado 2 del art. 20 (antes 18), y la nueva redacción dada por la Ley Orgánica 8/2000 al apartado 5 del art. 27 (antes 25) de la Ley Orgánica $4 / 2000$, por entender que los preceptos permiten que no se motive el acuerdo de denegación de visado en algunos supuestos, en concreto, cuando no se refieran a la reagrupación familiar o a la solicitud de permiso de trabajo por cuenta ajena. De ahí que se reputen contrarios a los arts. 24.1 CE (derecho a la tutela judicial efectiva) en relación con el art. 9.3 y 106.1 CE, ya que no se exige la motivación de una resolución administrativa, impidiendo su control jurisdiccional, lo que supone un menoscabo del derecho de defensa, además de alentar el carácter arbitrario de las decisiones de la Administración.

No obstante, como indica el TC en la STC 236/2007: " la exoneración del deber de motivación de los actos administrativos denegatorios del visado establecida en aquellos preceptos no debe reputarse contraria al art. 24.1 CE puesto que se trata de actos que no imponen sanción alguna ni limitan el ejercicio de ningún derecho fundamen- 
tal, como ha quedado expuesto. Por otra parte, aquella exoneración tampoco debe considerarse incompatible con la interdicción de la arbitrariedad de los poderes públicos (art. 9.3 CE) y con el obligado control de la actuación administrativa por parte de los Tribunales (art. 106.1 CE), que la Ley aquí enjuiciada garantiza «en todo caso, cuando el extranjero no se encuentre en España» (art. 65.2). (...)La inconstitucionalidad del precepto sólo podría sostenerse si la norma impugnada hubiera impedido el control jurisdiccional de estos actos administrativos basándose en su carácter potestativo o discrecional pues «con dicha fundamentación se niega la proyección que en este ámbito tiene la propia interdicción de la arbitrariedad de los poderes públicos que proclama el art. 9.3 CE» (STC 163/2002, de 16 de septiembre, FJ 5). Pero la Ley enjuiciada somete a control de los Tribunales esta actividad administrativa (art. 106.1 CE), con lo cual la Administración deberá estar en todo momento en condiciones de explicar que no ha ejercido de forma arbitraria sus facultades discrecionales».

3. Otro aspecto que puede afectar, por vía administrativa, al derecho constitucional a la defensa, lo constituye el «Procedimiento preferente de expulsión de extranjeros» regulado en el art. 63 de la Ley, por virtud de la cual se establece la ejecución inmediata de la sanción administrativa de expulsión, inconstitucionalidad que se aduce porque el plazo de cuarenta y ocho horas que se otorga al interesado para formular alegaciones en su defensa, tras la incoación del procedimiento sancionador, vulnera el art. $24 \mathrm{CE}$ en relación con el art. 6 del CEDH al producir indefensión, como se desprendería de la jurisprudencia del TEDH que se cita al efecto, por la indefensión que causaría la brevedad del plazo para alegaciones establecido en el precepto impugnado.

Tampoco en este caso entiende el TC que la regulación de este procedimiento pueda reputarse contraria al art. $24 \mathrm{CE}$, puesto que, aunque se trata de un procedimiento administrativo sancionador, ya que en estos casos la expulsión es «consecuencia de una conducta tipificada como infracción administrativa» (STC 116/1993, FJ 3), y por consiguiente le son aplicables los principios esenciales reflejados en el art. $24 \mathrm{CE}$ «en la medida necesaria para preservar los valores esenciales que se encuentren en la base del precepto y la seguridad jurídica que garantiza el art. $9 \mathrm{CE}$, (...), «la pretendida indefensión que generaría el precepto no es tal, pues hemos dicho reiteradamente que la brevedad de los plazos no implica per se la vulneración del derecho a la tutela judicial efectiva si con ello se tiende a hacer efectivo el principio de celeridad en el proceso, ya que es constitucionalmen- 
te inobjetable que el legislador prevea tal reducción en los plazos cuando dicha decisión responde a una finalidad razonable y necesaria, acorde con los principios que han de regir el procedimiento correspondiente (SSTC 14/1992, de 10 de febrero, FJ 8; 335/1994, de 19 de diciembre, FJ 3; 130/1998, de 16 de junio, FJ 5; 85/2003, de 8 de mayo, FJ 11). Tal es el caso de los supuestos previstos en el art. 63.1 de la Ley Orgánica 4/2000, como ha quedado argumentado, con la consecuencia de que el plazo establecido en el art. 63.2 no pueda reputarse contrario al art. 24 CE.(...) Por otra parte, ..., los extranjeros sometidos a este procedimiento preferente de expulsión disponen de las garantías esenciales del procedimiento administrativo, como el derecho de audiencia y el derecho a una resolución motivada, además del control judicial de la decisión que garantiza la misma Ley Orgánica al disponer que «las resoluciones administrativas sancionadoras serán recurribles con arreglo a lo dispuesto en las leyes» (art. 65, redactado conforme a la Ley Orgánica 8/2000).

4. La impugnación del punto $50 \mathrm{del}$ artículo primero de la Ley $8 / 2000$, que da nueva redacción a los apartados 2 y 8 del art. 57 (antes 53) de la Ley Orgánica 4/2000 por ser contrario a los principios de reeducación y reinserción social (art. 25.2 CE); y también por vulnerar el art. 25.1 CE puesto que supone una infracción del principio «non bis in idem", conectado con los principios de legalidad y tipicidad de las infracciones y sanciones (art. 25.1 CE), al establecer que la causa de la sanción administrativa es la misma que la de la sanción penal es rechazada por el TC al considerar que la expulsión contemplada en el precepto impugnado consiste en una medida que se acuerda legítimamente por parte del Estado español en el marco de su política de extranjería, en la que se incluye el establecimiento de los requisitos y condiciones exigibles a los extranjeros para su entrada y residencia en España, que no es un derecho fundamental del que aquéllos sean titulares con fundamento en el art. $19 \mathrm{CE}$ (STC 36/2007). Tampoco se reputa por el TC contrario al art. 25 de la CE la nueva regulación legislativa de los apartados 1, 5, 6 y 7 del nuevo artículo 57, referido a la expulsión del territorio. (STC 260/2007)

5. La impugnación del punto 53 del artículo primero de la Ley 8/2000, que da nueva redacción al art. 60 (antes 56) de la Ley Orgánica $4 / 20003$, por entender que vulnera el derecho a la libertad personal reconocido en el art. 17.1 y $2 \mathrm{CE}$, según la interpretación realizada por el Tribunal Constitucional (STC 115/1987), al no garantizar que más allá de las setenta y dos horas corresponda a un órgano judicial la decisión sobre el mantenimiento o no de la limitación de libertad, ya que de su redacción se desprende que el Juez no tendrá posibilidad de 
decidir otra cosa distinta al internamiento, es rechazada por el TC en la STC 236/2007, por considerar que «la voluntad de la ley, y desde luego el mandato de la Constitución, es que, más allá de las setenta y dos horas, corresponda a un órgano judicial la decisión sobre el mantenimiento o no de la limitación de la libertad.» (STC 115/1987). En consecuencia, para el TC, la expresión «para que determine el lugar donde hayan de ser internados hasta el momento del retorno", contenida en el precepto impugnado, debe ser entendida como equivalente a demandar o solicitar del juez la autorización para que pueda permanecer detenido el extranjero pendiente del trámite de expulsión más allá del plazo de setenta y dos horas, siendo el órgano judicial el que habrá de adoptar libremente la decisión. En sentido análogo se manifiesta el TC en relación con la impugnación de la medida cautelar prevista en el nuevo art. 61 b) de la L.O 4/2000 introducido por el apartado 54 del art. 1 de la L.O 8/2000, y en cuya virtud puede adoptarse, en el seno de procedimientos sancionadores en los que pueda proponerse la expulsión del extranjero, la medida cautelar consistente en la residencia obligatoria en determinado lugar, por no considerarse contraria al derecho a la libertad (SSTC 236/2007; 260/2007).

6. El último precepto impugnado es el apartado 55 del art. 1 de la L.O 8/2000 que da nueva redacción al art. 58 de la L.O 4/2000 que regula el plazo de duración máxima de la medida cautelar de internamiento adoptada durante la tramitación de un expediente sancionador en materia de extranjería, duración fijada en cuarenta días, por considerarse un sacrificio desmesurado de la libertad de las personas contrario al art. 17 CE y 5.1 f) CEDH. El TC, en la STC 260/2007, considera que el precepto impugnado "es plenamente respetuoso no sólo del art. 17.2 de la Constitución, sino, al mismo tiempo, también del art. 25.3, al no ser una decisión administrativa, sino judicial, la que permite la pérdida de libertad, pues no existe condicionamiento alguno sobre el Juez para decidir sobre esa libertad. Tampoco entraría el precepto en colisión con el art. 24.2 de la Constitución, porque del mismo no se deduce limitación alguna de los derechos de defensa del extranjero ni se impide su intervención en el correspondiente procedimiento".

\section{EFECTOS DE LAS SENTENCIAS. UN NUEVO RÉGIMEN DE DERECHOS Y LIBERTADES PARA LOS INMIGRANTES}

Como hemos indicado a lo largo de este estudio, uno de los efectos importantes de la reciente jurisprudencia constitucional en materia 
de derechos y libertades de los inmigrantes es que niega al legislador la posibilidad de restringir más allá de su contenido constitucionalmente declarado, interpretado de acuerdo con el Derecho Convencional Internacional, determinados derechos que, bien vinculados a la dignidad, o al libre desarrollo de la personalidad, fundamentos del orden político y la paz social (art. $10 \mathrm{CE}$ ), bien reconocidos por la Constitución a todas las personas dependientes de la jurisdicción estatal, no contemplan distinción entre las personas inmigrantes en razón de su situación administrativa. Reconocer la titularidad de estos derechos, y prohibir su ejercicio cuando la situación del inmigrante no está regularizada, es tanto como la negación del derecho en cuestión.

A través de la argumentación jurídica que hace el TC, se ha redefinido la potestad del legislador a la hora de regular los derechos y libertades de los inmigrantes, tomando como parámetro principal el propio Texto Constitucional, interpretado sistemáticamente, y en relación con los mandatos de los Convenios y Tratados como elemento interpretativo en materia de derechos.

Sin embargo, llama la atención de las sentencias, que el TC declare la inconstitucionalidad, pero no la nulidad ${ }^{14}$, de los artículos 7.1( derecho de reunión), 8 (derecho de asociación), y 11.1 (exclusivamente respecto al derecho a sindicarse libremente), considerando que no siempre es necesaria la vinculación entre la inconstitucionalidad y la nulidad: "así ocurre cuando «la razón de la inconstitucionalidad del precepto reside, no en determinación textual alguna de éste, sino en su omisión", máxime si tenemos en consideración que en lo que toca a los efectos de las sentencias de inconstitucionalidad, de acuerdo con lo dispuesto en la Ley Orgánica de este Tribunal (art. 39. 1), las disposiciones consideradas inconstitucionales han de ser declaradas nulas, declaración que tiene efectos generales a partir de su publicación en el «Boletín Oficial del Estado» (art. 38.1 LOTC) y que en cuanto comporta la inmediata y definitiva expulsión del ordenamiento de los preceptos afectados (STC 19/1987, fundamento jurídico $6 .^{\circ}$ ) impide la aplicación de los mismos desde el momento antes indicado, pues la Ley Orgánica no faculta al TC, a diferencia de lo que en algún otro sistema ocurre, para aplazar o diferir el momento de efectividad de la nulidad.

14 Este criterio ya ha sido utilizado con anterioridad por el TC, en concreto en las SSTC 45/1989, de 20 de febrero, FJ 11; 222/1992, de 11 de diciembre, FJ 7; 96/1996, de 30 de mayo, FJ 22; y 235/1999, de 20 de diciembre, FJ 13; 138/2005, de 26 de mayo, FJ 6. 
Si el TC ha reconocido los derechos de reunión y manifestación ; asociación y la libertad de sindicación, a todas las personas, su contenido constitucionalmente declarado extiende su ejercicio a todos, incluyendo a los extranjeros, con independencia de la regularidad de su situación, con estos pronunciamientos, el TC ha creado una ficción jurídica de difícil encaje, puesto que reconoce la titularidad de estos derechos y libertades a los inmigrantes y declara la inconstitucionalidad de la limitación de su ejercicio, pero no los expulsa del ordenamiento, y por lo tanto siguen siendo aplicables, a expensas de que el legislador, dentro de un plazo razonable regule su ejercicio por los extranjeros que no tienen autorización administrativa de estancia o residencia en España. La falta de un plazo temporal para que el legislador regule las condiciones de ejercicio de estos derechos, cuyo establecimiento no corresponde al TC, encargado exclusivamente del enjuiciamiento de la constitucionalidad normativa, dará lugar a que se sigan aplicando preceptos legales que han sido declarados inconstitucionales, que violan la Constitución.

El hecho de que el TC reconozca al legislador la posibilidad de optar por una de las varias opciones que, en materia de extranjería, caben en la Constitución, sin que le corresponda al TC realizar tal opción, puesto que no es el TC un órgano legislador, no es razón suficiente para que el TC alegue "vacío legal», puesto que no podemos olvidar que existen derechos y libertades reconocidos constitucionalmente que son directamente aplicables, que no exigen desarrollo legislativo o convencional para que su titularidad y ejercicio sean efectivos, por lo que en ningún caso, un posterior desarrollo legislativo puede atentar contra la forma en que han sido reconocidos constitucionalmente.

Con todo, la importancia de estas sentencias comentadas radica en que el Tribunal Constitucional establece un nuevo estatus en materia de derechos y libertades de los inmigrantes, declarando la inconstitucionalidad y nulidad de la regulación que hace la legislación de extranjería en relación con los derechos de educación; huelga y tutela judicial efectiva, reconocidos respectivamente en los arts. 27, 28 y $24 \mathrm{CE}, \mathrm{y}$, paralelamente, reconociendo la plena titularidad y el pleno disfrute de los mismos a los inmigrantes, independientemente de cuál sea su situación administrativa, y declarando la inconstitucionalidad de los preceptos legales que limitan, más allá de su contenido constitucionalmente declarado, los derechos de reunión, manifestación y asociación.

Este nuevo régimen en materia de derechos y libertades de los extranjeros, va a determinar que en el tratamiento de la igualdad entre 
nacionales y extranjeros, y entre estos últimos, dependiendo de cual sea la regularidad de su situación, no pueda establecerse ninguna distinción sobre determinados derechos y libertades, reconociéndose, por consiguiente su igualdad, por venir así proclamada constitucionalmente según la interpretación sistemática que el TC hace de nuestra Norma Fundamental.

Así, los inmigrantes, son titulares, y los ejercerán en las mismas condiciones que los nacionales, sin que, por lo tanto, las posibles leyes de desarrollo puedan establecer limitaciones específicas para ellos, de los siguientes derechos y libertades:

- Derecho a la vida (art. 15.1). Como ha indicado el Tribunal Constitucional, por su carácter imprescindible para la dignidad «corresponde a los extranjeros por propio mandato constitucional» (STC 107/1984, de 23 de noviembre).

- Derecho a la integridad física y moral (art. 15.1). Por su estrecha relación con la dignidad, no resulta posible un tratamiento desigual entre españoles y extranjeros (STC 107/1984, de 23 de noviembre).

- Derecho a la libertad ideológica, religiosa y de culto (art. 16.1). También se trata de derechos que impiden un tratamiento desigual entre españoles y extranjeros (STC 107/1984, de 23 de noviembre).

- Derecho a la libertad y a la seguridad (art. 17.1). "El derecho a la libertad del art. 17 CE es un derecho inherente a la persona humana, de aquellos que según la STC 107/1984, corresponden por igual a españoles y extranjeros» (STC 115/1987, de 7 de julio.).

- Derecho a la intimidad personal y familiar; a la propia imagen y al honor (art. 18.1). Sin el derecho fundamental a la intimidad no es imaginable la vida en dignidad que quiere asegurar la Constitución (SSTC 170/1987, de 30 de octubre; 20/1992, de 14 de febrero).

- Derecho a la inviolabilidad del domicilio (art. 18.2), y Derecho al secreto de las comunicaciones (art. 18.3). (STC 22/1984, de 17 de febrero).

- Derechos de libre expresión y de información (art. 20.1). (STC 62/1982, de 15 de octubre).

- Derecho de reunión y manifestación (art. 21). (STC 236/2007, de 7 de noviembre) 

viembre)

- Derecho de asociación (art. 22). (STC 236/2007, de 7 de no-

- Derechos reconocidos en el art. 24 CE. Los inmigrantes, en condiciones de igualdad con los españoles, disfrutarán del derecho a la tutela judicial efectiva, así como de las garantías procesales enunciadas como derechos fundamentales por el art. 24.2 CE, y que forman parte del contenido instrumental de la tutela judicial efectiva, y especialmente, dentro de ellas, del derecho instrumental a la asistencia jurídica gratuita (STC 95/2003, criterio mantenido por la STC 236/2007, de 7 de noviembre)

- Principio de legalidad penal (art. 25).

- En cuanto ostente la situación de recluso, el inmigrante disfrutará, en los mismos términos que la población reclusa nacional, de una serie de derechos vinculados indefectiblemente a su propia condición.

- Derecho a la educación obligatoria y no obligatoria (art. 27). (STC 236/2007, de 7 de noviembre)

- Derecho a la libertad sindical (art. 28.1). (STC 236/2007, de 7 de noviembre)

- Derecho a la huelga (art. 28.2) (STC 259/2007, de 19 de diciembre de 2007)

La titularidad del resto de derechos y libertades reconocidos constitucionalmente, y su forma de ejercicio, podrá ser delimitada por el legislador orgánico, teniendo en consideración la manera en que los reconoce la propia Constitución, interpretada de acuerdo con lo regulado por el Derecho Convencional Internacional, y con las limitaciones estudiadas.

A este nuevo estatus en materia de derechos y libertades de los extranjeros, habrá que añadir el estatus regulado por la legislación de extranjería. 